\title{
RMetS
}

Royal Meteorological Society

\section{Latent heat flux measurements over complex terrain by airborne water vapour and wind lidars}

\author{
Christoph Kiemle, ${ }^{\text {a }}$ Martin Wirth, ${ }^{\mathrm{a}}$ Andreas Fix, ${ }^{\mathrm{a}}$ Stephan Rahm, ${ }^{\mathrm{a}}$ Ulrich Corsmeier ${ }^{\mathrm{b}}$ and \\ Paolo Di Girolamo ${ }^{c}$ \\ a Institut für Physik der Atmosphäre, Deutsches Zentrum für Luft- und Raumfahrt (DLR), Oberpfaffenhofen, Germany \\ ${ }^{\mathrm{b}}$ Institute for Meteorology and Climate Research, Karlsruhe Institute of Technology (KIT), Germany \\ 'Dipartimento di Ingegneria e Fisica dell'Ambiente, Università degli Studi della Basilicata, Potenza, Italy \\ ${ }^{*}$ Correspondence to: C. Kiemle, Institut für Physik der Atmosphäre, Deutsches Zentrum für Luft- und Raumfahrt (DLR), \\ Oberpfaffenhofen, Germany. E-mail: christoph.kiemle@dlr.de
}

Vertical profiles of the latent heat flux in a convective boundary layer (CBL) are obtained for the first time over complex terrain with airborne water vapour differential absorption lidar and Doppler wind lidar. During the Convective and Orographically-induced Precipitation Study (COPS) over the Black Forest mountains in south-western Germany both lidars were installed nadir-viewing onboard the Falcon research aircraft of the Deutsches Zentrum für Luft- und Raumfahrt (DLR). On 30 July 2007, additional in situ measurements by the Karlsruhe Institute of Technology (KIT) were performed with a Dornier-128 aircraft that flew below the Falcon. This unique instrument configuration allows us to validate the lidar-derived fluxes and to assess lidar-specific issues such as instrument noise and data gaps that impinge on the results. The cospectra of in situ humidity and vertical velocity peak at wavelengths between 1 and $3 \mathrm{~km}$ and reveal that the dominant scales of turbulent transport are larger than $700 \mathrm{~m}$ in dimension. Consequently the airborne lidars' horizontal and vertical resolution of $\sim 200 \mathrm{~m}$ is sufficient to capture most of the flux. The lidar and in situ fluxes of five collocated $45 \mathrm{~km}$ flight legs agree within $\pm 20 \%$; the average difference over the total distance of $225 \mathrm{~km}$ is $3 \%$. A flux comparison with ground-based water vapour Raman and wind lidars shows agreement within the instruments' accuracies under low-wind conditions. All latent heat fluxes vary between 100 and $500 \mathrm{~W} / \mathrm{m}^{2}$ in the CBL and have small vertical divergences. Vertical velocity spectra in the mid-CBL enable us to estimate the dissipation rate of turbulent kinetic energy that amounts to $5 \times 10^{-4} \mathrm{~m}^{2} \mathrm{~s}^{-3}$ in the Rhine Valley and $10^{-3} \mathrm{~m}^{2} \mathrm{~s}^{-3}$ over the Black Forest mountains. This new airborne lidar instrumentation proves to be a valuable tool for the study of CBL processes and variability, particularly over complex terrain. Copyright (c) 2011 Royal Meteorological Society

Key Words: turbulent moisture flux; convective boundary layer; differential absorption lidar

Received 10 March 2010; Revised 29 November 2010; Accepted 30 November 2010; Published online in Wiley Online Library 18 February 2011

Citation: Kiemle C, Wirth M, Fix A, Rahm S, Corsmeier U, Di Girolamo P. 2011. Latent heat flux measurements over complex terrain by airborne water vapour and wind lidars. Q. J. R. Meteorol. Soc. 137: 190-203. DOI:10.1002/qj.757

1. Introduction

The sources of humidity in the troposphere are evaporation of the Earth's surface, of clouds and of raindrops. Turbulence in the convective boundary layer (CBL) efficiently mixes and transports humidity vertically. Water vapour is not only indispensable for precipitation but also, via its latent heat, controls the local thermodynamic equilibrium 
mainly responsible for the initiation of convection. Numerical weather prediction (NWP) model evaluations reveal that variations of humidity in the boundary layer have the largest impact on precipitation patterns (Keil et al., 2008; Dierer et al., 2009). Consequently more accurate and comprehensive measurements are needed to improve quantitative precipitation forecasts. Although evaporation, vertical and subsequent horizontal humidity transport constitute key elements of the hydrological cycle, they are still poorly modelled and observed, because most models must parametrize convective transport as a subgridscale process, and because water vapour observations are inaccurate due to instrumental limitations and high variability (Weckwerth et al., 1999, 2004). CBL processes and heat fluxes have therefore been a focus of field campaigns, laboratory studies and numerical models for decades, mostly however under homogeneous conditions over flat terrain.

Latent heat fluxes with statistical significance, representative for a specific area, are difficult to measure. Ground-based in situ measurements observe only the lowest part of the $\mathrm{CBL}$ and are influenced by local surface properties. Groundbased active remote sensing with lidar can profile the whole CBL (Senff et al., 1994; Giez et al., 1999; Wulfmeyer, 1999) and has recently become more widespread and reliable, also for heat flux measurements (Davis et al., 2009). However, low wind velocity gives poor area-representativity, and measurements over a long time period become biased by the CBL evolution. More flexibility and better sampling is obtained by airborne in situ instruments (e.g. Corsmeier et al., 2001), but the aircraft has to fly at stacked altitudes in order to obtain vertical profiles, which considerably limits the operational range. All these limitations do not apply to airborne remote sensing, where latent heat flux profiles beneath the aircraft are obtained from a single overflight of the region of interest by water vapour and wind lidars installed on board the same aircraft (Kiemle et al., 2007).

Mountains pose multiple investigative challenges due to their complex shapes that basically are incompatible with representative measurements and accurate modelling. A major reason for the failure of quantitative precipitation forecasts is that mountains impinge on the local CBL flow and turbulence structure, depending on the prevailing large-scale synoptic flow, differential solar heating, and land cover conditions. In addition, valley flows and convergence across the crests influence the initiation of convection (e.g. Behrendt et al., 2011, Bennett et al., 2011, Corsmeier et al., 2011). Precipitation in the low-mountain region in southwestern Germany (Black Forest) and eastern France (Vosges mountains) is caused by complex interaction between large-scale instabilities, modification of mesoscale flow by orography, and thermally induced orographic flow. The influence of thermally driven secondary circulations on convection initiation and its representation in a simulation model was studied during the VERTIKATOR (Vertikaler Austausch und Orographie - vertical exchange and orography) experiment in 2002 that revealed the importance of high-resolution models to improve forecasting in mountainous areas (Barthlott et al., 2006). Airborne in situ measurements during the VERTIKATOR experiment show latent heat fluxes with increased magnitude and variability over the Black Forest, in comparison to the Rhine valley (Hasel, 2006). This is related to the aforementioned particular flow conditions that interact with the CBL turbulence and increase it, as well as to a more heterogeneous

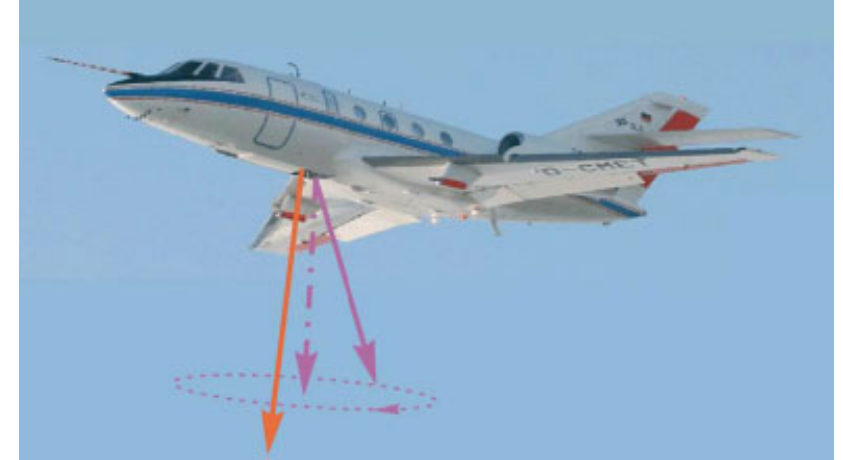

Figure 1. DLR Falcon research aircraft carrying wind (pink) and water vapour (orange) lidars during COPS 2007. The wind lidar can be operated either in conical scanning mode for estimates of the three-dimensional wind vector, or in nadir-viewing mode for profiling the vertical wind velocity below the aircraft, as in this study.

water vapour distribution due to higher variability of its sources, soil moisture and vegetation, in the mountains. The resulting spatial heterogeneity of the fluxes limits the representativeness of local measurements.

A recent Convective and Orographically-induced Precipitation Study (COPS) investigation based on Meteosat 'rapid scan' data revealed that the density of occurrence of convection initiation is about three times higher over the Black Forest and Vosges low-mountain ranges than in the Rhine valley which lies in between. Also, it exhibits a pronounced maximum two hours after local noon (Aoshima et al., 2008). The overarching goal of COPS is to improve the skill to forecast convective precipitation over complex terrain in the summer season (Wulfmeyer et al., 2008, 2011). It is expected that this can be reached by intensifying observational as well as modelling efforts, and by exploiting synergies from the combination of observations and models (e.g. Richard et al., 2011). The Deutsches Zentrum für Luftunf Raumfahrt (DLR) Falcon research aircraft participated in this experiment with nadir-pointing water vapour and wind lidars in similar configuration as during the International $\mathrm{H}_{2} \mathrm{O}$ Project (IHOP_2002: Weckwerth et al., 2004; Kiemle et al., 2007) (Figure 1). Three main objectives for the deployment of this unique airborne lidar instrumentation were defined: (1) Map the pre-convective mesoscale wind and humidity heterogeneity in a situation when deep convection and heavy precipitation were forecasted by flying a grid pattern across the COPS region. (2) Measure latent heat fluxes over the Rhine valley and the Black Forest when convection initiation was predicted to be mainly influenced by orography and surface humidity. (3) Perform targeted measurements across sensitive regions over southwest Europe located upstream of the COPS region, in the vicinity of an approaching trough with south-westerly flow, to quantify the subsequent humidity advection into the COPS area. Objective (2) is the topic of this work.

The DLR-Falcon activities were co-ordinated with other research aircraft and instrumented surface sites participating in the experiment, allowing for comprehensive intercomparisons. Table I lists all 14 mission flights, summing up to 46 flight hours. These COPS lidar data have already been used for the validation of weather prediction models (Schäfler et al., 2010; Chaboureau et al., 2011; Richard et al., 2011) and for a data intercomparison study (Bhawar et al., 2011). Four Falcon flights were dedicated to the objective of improving our understanding on the 
Table I. Overview of all 14 DLR-Falcon flights during COPS, including lidar mission objectives and authors that have used the data.

\begin{tabular}{|c|c|c|c|c|}
\hline COPS IOP & Date in 2007 & Measurement time (UTC) & Mission objectives & References \\
\hline $7 \mathrm{a}$ & 8 July & $0740-1040$ & Upstream & \\
\hline $7 \mathrm{a}$ & 8 July & $1240-1450$ & Upstream & \\
\hline $8 \mathrm{~b}$ & 15 July & $0610-0810$ & Flux & Richard et al.(2011) \\
\hline $9 \mathrm{a}$ & 18 July & $1310-1640$ & Map & Bhawar et al.(2011) \\
\hline $9 \mathrm{~b}$ & 19 July & $0650-0930$ & Upstream & \\
\hline $9 \mathrm{~b}$ & 19 July & $1120-1430$ & Upstream & \\
\hline $9 \mathrm{c}$ & 20 July & $0650-0920$ & Map & Bhawar et al.(2011) \\
\hline $9 \mathrm{c}$ & 20 July & $1100-1250$ & Map & \\
\hline $11 \mathrm{a}$ & 25 July & $1240-1550$ & Flux & \\
\hline $11 \mathrm{~b}$ & 26 July & $0850-1210$ & Flux & \\
\hline 12 & 30 July & $0950-1220$ & Flux & (this article) \\
\hline $13 \mathrm{a}$ & 1 August & $0410-0750$ & Upstream & \\
\hline $13 a$ & 1 August & $0910-1100$ & Upstream & Chaboureau et al.(2011) \\
\hline $13 a$ & 1 August & $1440-1720$ & Map & Schäfler et al.(2010) \\
\hline
\end{tabular}

initiation of convection over complex terrain by studying the spatial variability of humidity, wind and latent heat fluxes. To achieve this goal the following strategy was chosen for the Falcon flux missions: (1) High-pressure, fair-weather situations around local noon were selected where forcing of convection was expected to be dominated by surface fluxes. (2) Four standardized flight legs, displayed in Figure 2, were delineated above the Rhine valley (D) and the Black Forest (E, F, G), parallel to the Rhine valley and above some of the COPS ground-sites. (3) Mid-level $(\sim 5 \mathrm{~km})$ flight altitudes were chosen to obtain full CBL profiles. (4) The Rhine valley leg was devised as flat terrain reference. (5) The Falcon flux missions were co-ordinated with flights of the Dornier-128 in situ research aircraft operated by Karlsruhe Institute of Technology (KIT) and the Technical University of Braunschweig.

First analyses revealed that instrumental (lidar malfunctions), logistical (missed co-ordinated measurements) and meteorological (i.e. too many clouds) constraints made only the last of the four flux missions give enough substance for a case-study. The flight on 30 July 2007 is distinguished by low-noise lidar data, minor cloud cover, and collocated flux measurements with the Do-128 research aircraft and with ground-based lidars. The successful intercomparisons enable for the first time an in-depth verification of the latent heat flux estimation methods established for airborne water vapour and wind lidars by Kiemle et al.(2007). While that study had limited validation opportunities and exploited IHOP_2002 data over flat terrain, the lidar measurements here are for the first time performed over mountains, considerably augmenting complexity and interest, in line with the COPS objectives. This case-study consequently consists of a thorough analysis documenting lidar-related methodical issues, accuracy assessments, validations by collocated measurements, and the study of a post-frontal situation in which the latent heat flux plays a key role in the build-up of the CBL.

\section{Instruments}

The instruments contributing to this case-study include the DLR water vapour lidar, collocated with the Doppler wind lidar on board the Falcon research aircraft, the in situ sensors measuring wind and humidity on board the Dornier128 research aircraft of the University of Braunschweig and operated by KIT, and the ground-based water vapour Raman lidar operated by the University of Basilicata (Italy) and collocated with a Doppler wind lidar from the University of Salford (United Kingdom).

\subsection{The DLR WALES airborne water vapour lidar}

A differential absorption lidar (DIAL) sends short and spectrally narrow laser pulses into the atmosphere at a wavelength tuned to the centre of a molecular water vapour absorption line. The water vapour density can be derived from the difference in absorption between this 'on-line' and another 'off-line' non-absorbed laser pulse as function of distance from the lidar. The off-line reference backscatter signals contain information on the presence of aerosols and clouds. The DLR lidar group has long-term experience with latent heat flux profiling using ground-based (Giez et al., 1999) and airborne (Kiemle et al., 1997, 2007) DIAL, and with related data quality assessments (Behrendt et al., 2007a, 2007b). During the COPS experiment the newly developed 'WALES' water vapour DIAL (Wirth et al., 2009) was deployed for the first time. 'WALES' stands for 'Water vapour Lidar Experiment in Space' and is designed as an airborne demonstrator for a future DIAL mission on a satellite. Its four wavelengths (three on-line, one off-line) allow it to cover the large water vapour density variations encountered in the lower stratosphere and throughout the troposphere.

For COPS the WALES DIAL was installed nadirpointing on board the DLR Falcon research aircraft. Each of its two transmitters is based on an injection-seeded optical parametric oscillator (OPO) pumped by the second harmonic of a Q-switched, diode-pumped single-mode Nd:YAG laser at a repetition rate of $100 \mathrm{~Hz}$. The OPO is optimized for the spectral region between 920 and $950 \mathrm{~nm}$ where appropriate water-vapour absorption lines are found. Each transmitter emits two spectrally narrow pulses, yielding in total four pulses, each with $50 \mathrm{~Hz}$ repetition rate and $40 \mathrm{~mJ}$ energy at different suitable wavelengths. A 

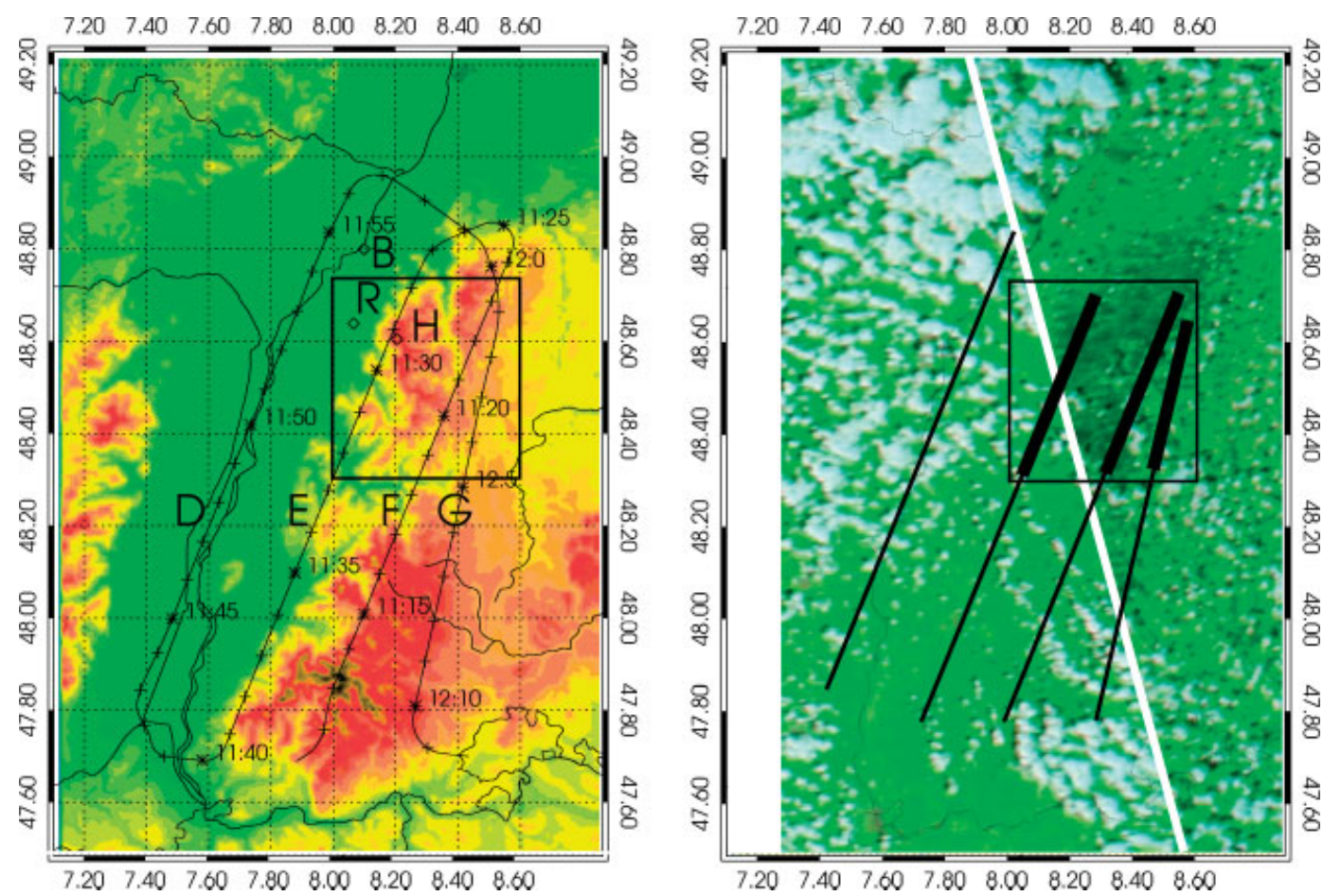

Figure 2. Left: DLR Falcon flight path on 30 July 2007 between 1111 and 1212 UTC over surface altitude from $150 \mathrm{~m}$ (green) to $1500 \mathrm{~m}$ asl (black). Plus signs are one-minute, asterisks five-minute intervals. Flight sequence: leg $\mathrm{F}$ in northward direction, E southwards, D northwards, and G southwards. The four flight legs are each $\sim 130 \mathrm{~km}$ long and oriented parallel to the Rhine valley, except leg $\mathrm{G}$ that had to obey air traffic control restrictions. The Dornier-128 aircraft operated within the box. The instrumented ground sites B (Baden-Airpark), R (Rhine valley) and H (Hornisgrinde) are indicated. Right: AQUA/MODIS images at 1130 (east of white line) and 1310 UTC (west) show cumulus clouds with slightly increasing cover over the measurement period (courtesy of NASA/GSFC, MODIS Rapid Response).

careful selection of lines with low temperature sensitivity, concerted line strengths and close wavelengths is essential. In the present study only the weakest absorption line, best suited for CBL measurements, is used. In order to reduce instrument noise the individual on- and off-line DIAL profiles are accumulated to $1 \mathrm{~s}$ averages, which results in a horizontal resolution of $170 \mathrm{~m}$ at the typical aircraft speed of $170 \mathrm{~m} / \mathrm{s}$ flown here. The DIAL equation is applied with an effective vertical resolution of $200 \mathrm{~m}$. The residual noise leads to a precision of $\sim 0.4 \mathrm{~g} / \mathrm{kg}$ or $10 \%$ of the mean CBL specific humidity of $4 \mathrm{~g} / \mathrm{kg}$ encountered in this study. Data intercomparisons reveal that the WALES accuracy during COPS is $\sim 2 \%$ or $\sim 0.1 \mathrm{~g} / \mathrm{kg}$ (Bhawar et al., 2011).

\subsection{The DLR airborne Doppler wind lidar}

The DLR $2 \mu \mathrm{m}$ Doppler wind lidar with heterodyne detection (Weissmann et al., 2005) possesses two rotating refractive wedges that deflect the lidar beam off-nadir such that it performs conical scans, as illustrated in Figure 1. Schäfler et al. (2010) exploit horizontal wind profiles derived from these measurements to estimate humidity advection. For vertical wind velocity profiling, both wedges are positioned such that the beam is deflected in the nadir direction. The aircraft roll and pitch angles are used to correct the beam direction by repositioning the wedges every second. During straight flight legs the resulting off-nadir deviation is $<0.08^{\circ}$. The residual wind uncertainty is eliminated using the ground return signal as zero wind reference. The vertical resolution is $100 \mathrm{~m}$. The individual profiles are accumulated to $1 \mathrm{~s}$ averages in order to match the DIAL's horizontal resolution. Atmospheric backscatter profiles are used for alignment and quality control. Invalid wind velocity
Table II. Airborne water vapour and wind lidar system characteristics.

\begin{tabular}{lll}
\hline & $\begin{array}{l}\text { Water vapour } \\
\text { DIAL }\end{array}$ & $\begin{array}{l}\text { Doppler wind } \\
\text { lidar }\end{array}$ \\
\hline Wavelength (nm) & 935 & 2023 \\
Pulse energy (mJ) & 40 & 1.5 \\
Pulse rep. freq. (Hz) & 200 & 500 \\
Average power (W) & 8 & 0.75 \\
Telescope diam. (m) & 0.48 & 0.10 \\
Horizontal res. (m) & 170 & 170 \\
Vertical res. (m) & 200 & 100 \\
Precision (noise) & $0.4 \mathrm{~g} / \mathrm{kg}$ & $0.1 \mathrm{~m} / \mathrm{s}$ \\
Accuracy (bias) & $0.1 \mathrm{~g} / \mathrm{kg}$ & $0.1 \mathrm{~m} / \mathrm{s}$ \\
\hline
\end{tabular}

The average DLR-Falcon speed was $170 \mathrm{~m} / \mathrm{s}$, which gives the indicated horizontal resolution for the $1 \mathrm{~s}$ averaged water vapour and wind profiles.

estimates are efficiently removed by a threshold for too-low backscatter signals. The few occasionally remaining outliers are removed individually. An overview of the main system characteristics of both airborne lidars is given in Table II.

\subsection{The Dornier-128 research aircraft}

The two-engine research aircraft Dornier 128-6 is operated by the University of Braunschweig. Details with special emphasis on the avionic equipment, data acquisition and the meteorological sensors are given in Corsmeier et al.(2001). The aircraft's nose boom contains redundant sensors for the measurement of wind, temperature and humidity. It is made 
of highly modular carbon fibre and has an eigenfrequency of approximately $20 \mathrm{~Hz}$ with negligible resonance rise. The data of air speed, angle of attack and angle of side-slip as well as the static pressure are measured at the tip of the nose boom by a Rosemount 5-hole probe and pressure transducers, mounted directly in the sensor compartment at the tip of the boom. The wind velocity is calculated from the difference between the air speed vector and the flight path speed vector at a rate of $100 \mathrm{~Hz}$ using combined inertial navigation system and GPS (Global Positioning System) navigation. The reliability is confirmed by Fourier spectra up to a frequency of $30 \mathrm{~Hz}$ for all flight legs analysed in this study. During COPS the mean ground speed was $65 \mathrm{~m} / \mathrm{s}$, resulting in a spatial measurement resolution of $<1 \mathrm{~m}$. The accuracy of the vertical velocity is $0.1 \mathrm{~m} / \mathrm{s}$. Humidity is measured with an Aerodata/Vaisala Humicap, a Meteolabor dew-point mirror at low frequency and a Lyman-alpha humidity unit at high frequency up to $25 \mathrm{~Hz}$. To avoid falsification of the signal by cloud liquid water the Lyman-alpha sensor is mounted in a cross-flow housing. The Humicap and Lyman-alpha signals are filtered complementarily using the low frequencies of the Humicap and the high frequencies of the Lyman-alpha instrument. After pressure correction there is no evident influence of the true air speed on the temperature and the humidity signal. For low frequencies the spectral energy density of the Humicap is only a little smaller than that of the Lyman-alpha. The spectrum of the filtered time series is in between the spectra of both instruments for low frequencies and identical with the Lyman-alpha spectrum for the high frequency range, reaching a time constant of $0.04 \mathrm{~s}$. The specific humidity has an accuracy of $4.8 \%$.

\subsection{The ground-based water vapour and wind lidars}

During COPS 2007 the University of Basilicata Raman Lidar system (BASIL: Di Girolamo et al., 2009) was installed zenith-pointing at 'supersite' R in the Rhine valley in Achern, $5 \mathrm{~km}$ to the west of the Black Forest foothills (Figure 2). Water vapour profiles are computed from the vibrational Raman backscatter signals at 387 and $407 \mathrm{~nm}$ from nitrogen and water vapour molecules, respectively. They are calibrated with Vaisala RS-92 radiosondes that were regularly launched at the site during COPS. Intercomparisons with airborne water vapour lidars and other independent hygrometers confirm the accuracy of the BASIL results (Bhawar et al., 2011). The collocated University of Salford scanning $1.5 \mu \mathrm{m}$ Doppler wind lidar, employing novel fibre-optic technology with a high level of performance and stability, was zenithoriented like BASIL for the latent heat flux profiling episodes (Davis et al., 2009).

\section{Airborne Lidar Flux Retrieval Method}

The in situ measurements by the Dornier-128 aircraft on 30 July 2007 collocated with the Falcon lidar measurements enable for the first time an in-depth verification of the latent heat flux methods and accuracy analyses established for airborne water vapour and wind lidars by Kiemle et al.(2007). This includes critical questions such as the coalignment of the lidar beams, the influence of data gaps and instrument noise, as well as particularities in correlation and spectral analyses. These lidar-specific issues are not treated in textbooks on statistics, time-series analyses or spectral transformations. For multi-purpose tests, uninterrupted, noise-free 5-Hz-averaged time series of humidity and vertical velocity by the Do-128 aircraft were chosen between 1129 and 1141 UTC at $1400 \mathrm{~m}$ above sea level (asl) $\left(\sim 0.8 z_{i}\right.$; inversion height) and with a length of $47 \mathrm{~km}$ over the northern Black Forest. First, a reference set of statistical parameters and spectra is generated with the original data. Then, artificial gaps are introduced and white noise is added to simulate the lidar data, and the results are compared to the reference.

\subsection{Co-alignment of airborne lidars}

A critical issue of airborne lidar flux measurements is the coalignment of the water vapour and wind lidar beams. While the wind lidar is pointing nadir to within $0.08^{\circ}$ as explained in section 2.2, the DIAL beam is constantly perpendicular to the aircraft horizontal axis due to mechanical set-up constraints. This gives a DIAL off-nadir pointing equal to the pitch angle between the horizontal aircraft axis in flight direction and the horizon, as illustrated, slightly exaggerated, in Figure 1. During all straight flight legs the angle was $4.0 \pm 0.2^{\circ}$ which gives a misalignment of $350 \mathrm{~m}$ at a maximum distance (flight altitude) of $5 \mathrm{~km}$. This angular offset between both beams is corrected by a range-dependent lateral shift of the DIAL time series relative to the wind lidar data. The resulting alignment of both time series is better than the horizontal resolution of $170 \mathrm{~m}$ when comparing both lidars' backscatter signals from the surface and clouds.

\subsection{Lidar data gaps}

Gaps in lidar measurements are almost inevitable. Clouds, aircraft turns or lidar readjustment phases cause fully or partly unusable profiles that form gaps of irregular size in a two-dimensional lidar cross-section. For spectral and correlation analyses the gaps cannot be bridged by interpolation, and even less can the valid data be simply pasted together. This would destroy the phase relation of turbulent structures. To minimize the gap frequency the lidars were usually readjusted close to the ends of the flight legs. Most gaps are from opaque, small cumulus clouds that formed at the CBL top on 30 July 2007. Cloud detection is efficiently implemented by a backscatter intensity threshold. Variances and covariances are calculated in the usual way after zero-padding the gaps. Multiplying the results with the factor $n / n_{\text {valid }}$ compensates the reduction in variance by the gaps. Here, $n$ is the number of total data points and $n_{\text {valid }}$ the amount of gap-free data points.

The impact of gaps is examined using the Do-128 in situ test time series introduced above. First, the data gap behaviour of the fast Fourier transformation (FFT) is verified. For reference, a least-squares best fit of sine and cosine waves (Stull, 1988) to the test time series containing irregularly spaced gaps is computed. To produce a spectrum comparable to the FFT result, the fit is repeated for all corresponding frequencies. Both transformations give nearly identical results if the gaps in the time series for the FFT are zero-padded, which is to be expected in view of the Fourier coefficients' characteristics. The presence of steps at the gap borders slightly increases the FFT spectral level by a few percent. Like the variances, the Fourier spectra have to be normalised with the factor $n / n_{\text {valid }}$. In conclusion, zeropadding the gaps with subsequent variance normalisation is an appropriate solution for (co-)variances, spectra and auto- 
and cross-correlation functions of the humidity and wind data. To study the effect of gaps on the resulting humidity fluxes, the original uninterrupted in situ time series serve as reference. Then, gaps with the size and spacing of the real, lidar-observed clouds with a cloud cover of $14 \%$ are inserted. The flux is reduced by $11 \%$ compared to the cloudfree reference. The reduction is likely due to the fact that the missed fluxes beneath clouds are stronger in cases when the clouds are growing and releasing latent heat (Giez et al., 1999). This bias is however small compared to the flux uncertainties detailed below.

\subsection{Computing spectra and cospectra}

While plenty of literature exists on the topic, specific lidar data issues are investigated in this study and verified using the in situ test data. For example, correct normalisation of the spectra is a prerequisite for proper flux calculations based on cospectra. The term 'spectrum' is commonly used here to designate the energy spectrum, i.e. the squared absolute value of the complex one-sided FFT. Generally most FFT applications focus on the shape and slope of the spectrum rather than on its density level that is related to the variance; therefore the spectral level is not treated in depth in textbooks. Another issue concerns appropriate data conditioning, i.e. preparation of the time series such that the FFT can correctly be applied. It includes the removal of mean value and linear trend, and the application of a data window in order to reduce what is called leakage in the spectra (Stull, 1988). Leakage is related to the convolution theorem: the multiplication of the time series with the window function corresponds to the convolution of its spectrum with the Fourier transformed window. Our tests show that data windowing consequently smoothes the spectrum, as expected and desired. While conditioning is often seen as a standard procedure, our tests reveal that it can severely alter significant statistical parameters and hence has to be applied with caution and economy.

First, multiplication of the time series with a data window leads to a reduction of the variance. If $n$ is the number of data points and $W$ the window function, the variance is reduced by a factor equal to the third term of Eq. (1) (Press et al., 1988). Here we use the Hanning window, $W(k)$ $=0.5 \cdot(1-\cos (2 \pi k / n))$. Other common window functions were tested; similar shaped functions give nearly identical results. On the other hand, flat-topped windows that rise and fall relatively quickly at the beginning and the end are found ineffective because they behave like a square window, i.e. like no window at all, as noted by Press et al.(1988). To obtain the correct variance, normalisation is mandatory. The resulting energy spectrum then adopts the form

$$
S_{x}(f)=\frac{2}{\Delta f} \cdot \frac{n}{n_{\text {valid }}} \cdot \frac{n}{\sum_{k=1}^{n} W(k)^{2}} \cdot\left|S_{\mathrm{FFT}}(W \cdot x, f)\right|^{2} .
$$

Here, the factor of two accounts for the one-sided spectrum, while the second and third terms restore the variance lost by gaps and the data window $W$, respectively. $S_{F F T}$ is the complex one-sided FFT result of time series $x$ at frequency $f$, where $x$ stands for the de-trended time series, i.e. for the fluctuations of either specific humidity $q^{\prime}(\mathrm{g} / \mathrm{kg})$ or vertical velocity $w^{\prime}(\mathrm{m} / \mathrm{s})$. Given the time series duration $T$, the spectrum spans frequencies ranging from $\Delta f=1 / T$, the fundamental frequency, to $n /(2 \cdot T)$, the Nyquist frequency, that equals half the data sampling frequency. Far more interesting than the frequencies are the spatial scales or wavelengths $\lambda$ of the sampled atmospheric structures or waves. For airborne measurements at constant airspeed $v$, Taylor's hypothesis of 'frozen turbulence' relates frequencies to wavelengths via $\lambda=v / f$. Given the time series length $L=v \cdot T$, the spectrum spans wavelengths ranging from $L$, the fundamental wavelength, to $2 \cdot L / n$, the Nyquist wavelength. Likewise, the cospectrum of $w^{\prime}$ and $q^{\prime}$ is

$$
\begin{array}{r}
C o_{w q}(f)=\frac{2}{\Delta f} \cdot \frac{n}{n_{\text {valid }}} \cdot \frac{n}{\sum_{k=1}^{n} W(k)^{2}} \\
\Re\left(S_{F F T}^{*}\left(W \cdot q^{\prime}, f\right) \cdot S_{F F T}\left(W \cdot w^{\prime}, f\right)\right) .
\end{array}
$$

The asterisk denotes the complex conjugate, the gothic $\mathrm{R}$ the real part of the complex argument. The cospectrum is of particular interest as it illustrates the relevant spatial scales at which the turbulent flux transports humidity. Following the correlation theorem, its integral equals the covariance $\left\langle w^{\prime} \cdot q^{\prime}\right\rangle$ which gives the total net flux (Press et al., 1988; Stull, 1988; brackets indicate ensemble averages). The cospectrum integral is also equal to the zero-lag value of the cross-covariance function (CCF) of $w^{\prime}$ and $q$ '. Likewise, for the variances, the integral of the energy spectrum equals the autocovariance function at lag zero, as well as the variance of the time series of $w^{\prime}$ or $q$ ' according to the Wiener-Khinchin theorem. The following equations illustrate these analogies, whereby Eqs (1) and (2) are normalised such that their integral over the frequency range fulfils these relations:

$$
\int_{f=1 / T}^{n /(2 T)} S_{x}(f) \mathrm{d} f=\sigma_{x}^{2}, \int_{f=1 / T}^{n /(2 T)} C o_{w q}(f) \mathrm{d} f=<w^{\prime} \cdot q^{\prime}>
$$

For discrete time series and spectra, the integral is a summation and $\mathrm{d} f$ becomes $\Delta f$. The analogies are particularly useful to verify the consistency of the time series and the validity of all normalisations and transformations. Variances and covariances were computed using these three mathematically identical methods for all lidar and in situ flight legs. While the directly computed covariance $<w$ ' $\cdot q>$ and the CCF's zero lag value give identical results, the cospectrum integral shows minor deviations that we attribute to the smoothing effect of the FFT's data window. We observe similar results for the variances. All flux profiles in the following sections represent the covariance $\left\langle w^{\prime} \cdot q^{\prime}\right\rangle$.

\subsection{Lidar instrumental noise}

Like data gaps, instrumental noise is inherent to lidar measurements. Noise from various sources, e.g. the laser photons' shot noise, the random character of the atmospheric scattering process, and detector and amplifier noise, is superposed on the lidar signals. The different noise sources are not correlated with each other, and subsequent lidar profiles are independent measurements. This allows the separation of the noise from the pure atmospheric variability because the uncorrelated noise is superposed as a peak on the autocovariance function's zero lag (Kiemle et al., 1997; Lenschow et al., 2000). The different wavelengths and detection principles of both airborne lidars (Table II) lead 
to different noise characteristics. Due to the wind lidar's heterodyne detection principle, signals from regions with high aerosol load such as the CBL are almost noise-free and only occasionally contaminated by outliers easy to detect and remove. However, the $2 \mu \mathrm{m}$ lidar necessitates so strong an aerosol backscatter that wind data in layers with low aerosol content are lacking. On the other hand the water vapour data have a high noise level due to the double differentiation between the on- and off-line signals and over the range in the DIAL retrieval. The DIAL noise increases with distance from the lidar and with decreasing optical depth, i.e. water vapour density. In this respect nadir-pointing airborne lidars offer a considerable advantage over ground-based zenithpointing systems since the increasing water vapour and aerosol densities nearly compensate the signal losses in the far range.

With the nearly noise-free in situ data of the Do-128 aircraft we examined the effect of noise on the flux results using normally distributed random numbers to simulate uncorrelated noise. The artificial noise level was matched to the DIAL data noise of $\sim 0.15(\mathrm{~g} / \mathrm{kg})^{2}$, expressed as specific humidity variance, which corresponds to a standard deviation of $\sim 0.4 \mathrm{~g} / \mathrm{kg}$ or $10 \%$ of the mean CBL humidity of $4 \mathrm{~g} / \mathrm{kg}$. The wind lidar data are nearly free of noise and maintained. In another run the $q$ noise was augmented to $1(\mathrm{~g} / \mathrm{kg})^{2}$ in order to test excessive conditions. While the humidity spectrum is, as expected, severely altered, the magnitude of the flux remains unchanged when computed from the covariance $\left\langle w^{\prime} \cdot q^{\prime}\right\rangle$ or the CCF's zero-lag value. The $w^{\prime} q$ ' cospectrum integral increases by a few percent, but only in the extreme case of $1(\mathrm{~g} / \mathrm{kg})^{2}$ noise variance. The cospectrum becomes noisier at the high-frequency end, but its low frequencies remain unaffected. The tests reveal that the CCF becomes less reliable at larger lags, but remains nearly noise-free overall. The noise-indifference of the covariance is due to the fact that the noise is not correlated with atmospheric turbulence.

\subsection{Eddy covariance}

Turbulence by buoyant eddies in the CBL generates an efficient vertical humidity transport in either the upward or downward direction, depending on the location of sources and sinks of water vapour. In our case the CBL humidity transport is directed upward, from evaporation as surface source to cloud condensation and entrainment into the drier free troposphere as sinks, as the flux profiles in the next section will show. A representative net flux is obtained from the covariance of vertical velocity and specific humidity fluctuations $\left\langle w^{\prime} \cdot q^{\prime}\right\rangle$ in a given time or space domain under the conditions that the turbulence is quasi-stationary over time and spatially homogeneous. These conditions are not fulfilled in the lower part of the CBL, particularly over complex terrain. However, due to DIAL retrieval limitations, humidity data are not available below $200 \mathrm{~m}$ agl anyway. A vertical profile of the flux is obtained from the twodimensional $w$ and $q$ lidar cross-sections by computing the covariance of segmented and de-trended $w^{\prime}$ and $q$ ' time series for each altitude. The vertical separation is $100 \mathrm{~m}$, corresponding to the vertical resolution of the wind lidar profiles. Since no further vertical averaging is applied, this equals the vertical resolution of the resulting flux profiles. To avoid under-sampled mesoscale contributions to the flux, the $1 \mathrm{~Hz} w$ and $q$ time series are split into individual half-overlapping segments of 64 s length each. With a Falcon flight speed of $170 \mathrm{~m} / \mathrm{s}$ on average, the segments' lengths are $\sim 11 \mathrm{~km}$. For each segment, mean value, variance and covariance profiles are determined, and FFT spectra are computed in the way described above. Finally, the results are accumulated over all segments of a flight leg as detailed in Kiemle et al.(2007). This considerably improves the statistical significance in the context of relatively short flight legs and noisy data, and is superior to conventional high-pass filter methods that modify the data.

A DIAL measures the water vapour molecule number density from which, using the ideal gas equation with pressure and temperature profiles obtained from nearby radiosondes, the dry air water vapour mixing ratio $m$ is obtained. The relative difference to the specific humidity $q$ is lower than $1 \%$ in the present study, since $q=m /(m+1)$, and therefore neglected. The specific humidity flux $<w$ ' $\cdot q^{\prime}>(\mathrm{g} / \mathrm{kg} \mathrm{m} / \mathrm{s})$ is converted into the flux of latent heat $\left(\mathrm{W} / \mathrm{m}^{2}\right)$ by multiplication with the air density $\rho$ obtained from the radiosonde and the latent heat of vaporization of water $L_{\mathrm{v}}$. Both $\rho$ and $L_{\mathrm{v}}$ generally increase with decreasing temperature and thus partly compensate the decrease of $\rho$ with height in a vertical CBL profile of the product $\rho L_{\mathrm{v}}$. For the fluxes presented in the next section, $\rho L_{\mathrm{v}}$ at the CBL top is only $8 \%$ smaller than at the surface. This justifies the use of a constant product $\rho L_{\mathrm{v}}$ that amounts to $2.7 \mathrm{MJ} / \mathrm{m}^{3}$ in this case-study and allows displaying both the humidity and the latent heat flux profiles in one plot. The Webb correction, that accounts for dry air density fluctuations when number densities are measured, increases the fluxes by $5 \%$ at the surface and by $1 \%$ at the CBL top, following the approach documented in Kiemle et al.(2007), and assuming a surface sensible heat flux of $180 \mathrm{~W} / \mathrm{m}^{2}$ as measured by a KIT-operated energy balance station.

A final verification step using the in situ test data consisted of comparing the results of the above-described algorithms with procedures used at KIT (Hasel, 2006). Variances, fluxes and integral length scales (integrals over the autoand cross-covariance functions) are found to agree within $\pm 10 \%$. The deviations are probably due to slightly different segmentation. Spectra and cospectra also agree well. As it is unlikely that both algorithms give equally wrong results this corroborates the validity of our methods.

\section{Latent Heat Fluxes and Comparisons}

On 30 July 2007 the COPS region was influenced by the back side of a trough with moderate northwest wind in the lower troposphere. An associated cold front caused rain on the two previous days. A small to medium probability of deep convection, initiated by local effects and surface fluxes, had been forecasted and led to the decision to fly a flux mission. During the day, cumulus clouds developed (cf. Figure 2) but no precipitation was observed. Lidar measurements from the four consecutive DLR Falcon flight legs of Figure 2 are discussed in detail in the following, together with airborne in situ and ground-based lidar fluxes used for comparisons.

\subsection{Airborne lidar measurements over the mountains}

An exemplary result of airborne lidar measurements on 30 July 2007 above the northern Black Forest is shown in Figure 3. The fourfold plot gives an overview of the lidar measurements of aerosol backscatter, vertical velocity and 


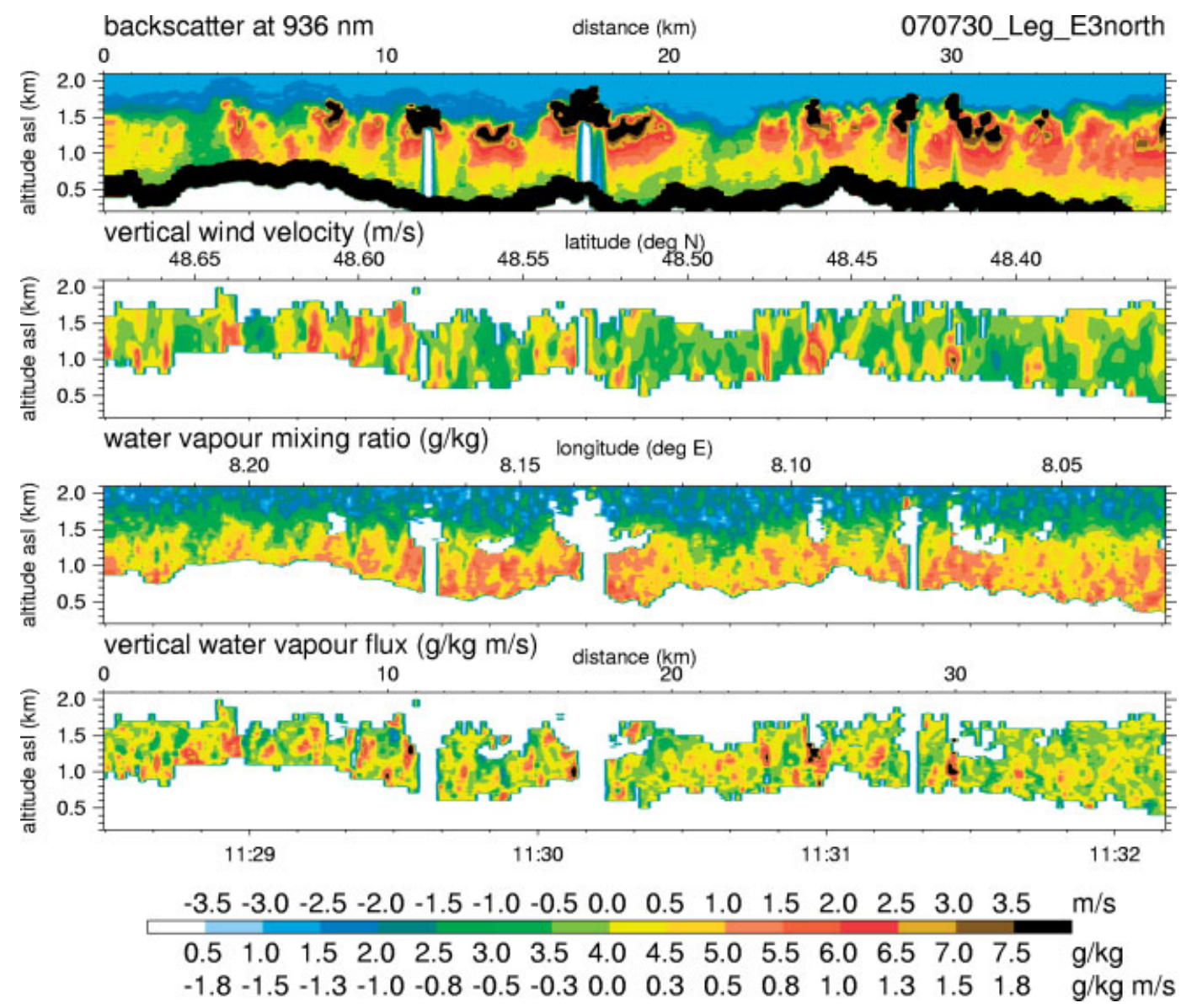

Figure 3. Aerosol backscatter intensity (in arbitrary units; top), vertical motion (updraughts positive), humidity and water vapour flux above the Black Forest on 30 July 2007 over the northern part of flight leg E. The Hornisgrinde Mountain (H in Figure 2) was overflown at 1129 UTC. Local time is two hours ahead. The aspect ratio is $\sim 1: 3$, the average CBL depth is $\sim 1 \mathrm{~km}$. Convection, cumulus clouds and orographic influences produce an irregularly structured boundary layer. A few intense updraughts generate most of the flux.

humidity. The DIAL off-line signals' backscatter intensity displays the orography (black), the CBL complexity and the clouds forming at the CBL top (black). The backscatter contrast with the free troposphere above provides a precise indication of the irregular CBL top. The Doppler wind lidar's profiles accurately reproduce the convective up- and downdraughts of varying size and strength. Due to low backscatter there are no wind data in the free troposphere above the CBL. The DIAL humidity plot shows the contrast between the CBL with $4.5 \mathrm{~g} / \mathrm{kg}$ on average over this leg and the drier free troposphere $(2 \mathrm{~g} / \mathrm{kg})$. White areas are gaps due to clouds and mountains.

The bottom plot of Figure 3 is the product of $w^{\prime}$ and $q$ at each individual data point, not equal to the covariance of $w^{\prime}$ and $q$ ', and represents the local up- and downward humidity transport. Humid updraughts generate the largest positive fluxes, e.g. near the Hornisgrinde mountain top (1129 UTC) or in the vicinity of clouds (1131). This is expected, as mountain tops may act as 'hot spots' for convection, and as the cloud-induced flux beneath growing clouds, generating additional buoyancy through release of latent heat, can be considerable (Giez et al., 1999). Dry downdraughts (negative $w^{\prime}$ and $q^{\prime}$ ) also produce a positive flux, e.g. at 11:28:50, whereas humid downdraughts (e.g. at 11:31:34) generate a negative flux. However, it is evident that the humid updraughts dominate, giving a positive overall net flux, as shown in the next section. The product of $w$ and $q$ ' provides an impression of the spatial distribution and scale of turbulent elements that significantly contribute to the net flux. A few large thermals appear responsible for most of the flux. Their locations are not generally found above mountain tops or warm southward-oriented slopes as one would expect, because secondary circulations such as valley or mountain-plain winds may shift and blur the 'hot spot' patterns. Similarly, the variability of $w, q$ and the CBL top seems unrelated to orography. Figure 3 shows that the separation of mesoscale variability, mountain circulations and turbulent transport is not straightforward. The threedimensional complexity of the scene calls for additional cross-track data that are lacking at present. Basically, the mountain circulations are expected to have scales larger than the turbulent scales and could hence be separated by spectral analysis.

\subsection{Fluxes over the mountains}

Collocated Dornier-128 in situ measurements were undertaken within the CBL in the northern part of the Black Forest on the northern half of the legs E, F, and G between 48.3 and $48.7^{\circ} \mathrm{N}$. The flight legs are $\sim 45 \mathrm{~km}$ long, at altitudes between 800 and $1400 \mathrm{~m}$ asl corresponding approximately to $0.2-0.8 z_{i}$, and highlighted as bold lines within the box of Figure 2. The Falcon being roughly twice as fast as the Do128 , the latter aircraft flew half-length legs. Co-ordination was such that both aircraft crossed in the northern Black Forest, exact collocation occurring four times on that day. 


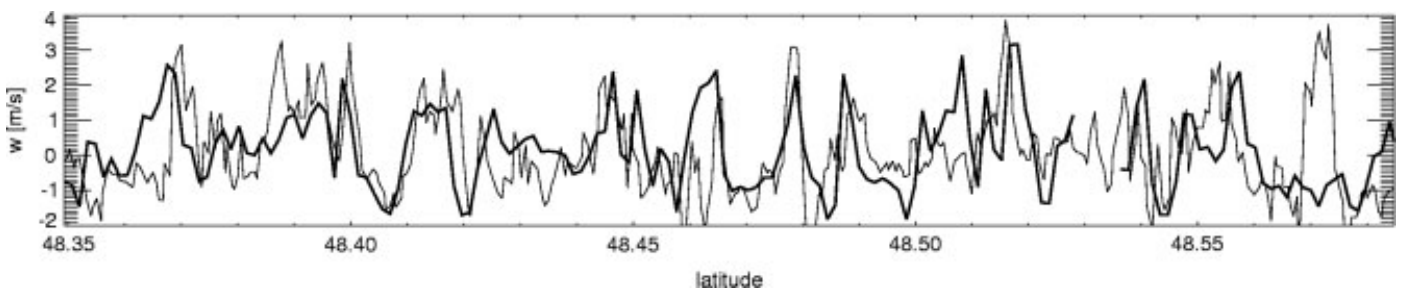

Figure 4. Vertical wind velocity from the Falcon wind lidar (thick) and the Dornier-128 in situ sensor (thin; $1 \mathrm{~Hz}$ averages) in the mid-CBL at $1120 \mathrm{~m}$ asl as function of latitude. The length is $29 \mathrm{~km} ; 1 \mathrm{~km}$ is $\sim 0.01^{\circ}$. Both aircraft were flying over the northern part of leg F between 1119 and $1122 \mathrm{UTC}$. Thanks to the excellent collocation $(<200 \mathrm{~m})$ even small-scale updraughts (positive $w$ ) are identical in both time series. As expected, the skewness is very pronounced, the updraughts being stronger than the downdraughts.

Radiosondes and the Do-128 aircraft ascent and descent profiles show that the average CBL wind was from north-west and with $\sim 2.5 \mathrm{~m} / \mathrm{s}$ so weak that free convection dominated. To assess convection intensity, the free convection scaling velocity $w^{*}$ (e.g. Stull, 1988) is estimated from the Do-128 sensible heat flux measurements over the Rhine valley. A $w^{\star}$ value of $\sim 1.5 \mathrm{~m} / \mathrm{s}$ is obtained, leading to a free convection time scale of $\sim 15$ minutes at an average valley CBL thickness of $1300 \mathrm{~m}$. Since this is the typical time for one convective turnover, measurements separated by this duration are expected to be anticorrelated, and intercomparisons have to be much closer in time.

The flight segment with the best collocation of wind measurements is shown in Figure 4. Here the crosstrack separation between both measurements is smaller than $200 \mathrm{~m}$, taking into account the time separation and the transport by the mean CBL wind whose fluctuations may explain occasional deviations. A similar collocation succeeded on another flight leg with comparable results. The leg-averaged difference between the lidar and the in situ vertical velocity is $<0.15 \mathrm{~m} / \mathrm{s}$ for these two best-match cases, which corroborates the instruments' accuracy estimations and constitutes an excellent result for both measurements. The area covered by updraughts is not significantly smaller than the area covered by downdraughts; the mean velocity is zero. The other two flight legs had average spatial separations of $600 \mathrm{~m}$ and temporal separations of up to 7 minutes. While here both wind measurements are as expected not correlated, the humidity remains correlated despite the larger separations. As Figure 3 shows, it varies on larger scales than the vertical velocity because surface evaporation with subsequent advection, the source of humidity, adduces variability on larger scales than buoyancy, the generator of vertical velocity. All four collocated flight legs confirm that wind intercomparisons are possible to within $\sim 500$ $\mathrm{m}$ spatial separation, while humidity is correlated within $\sim 1000 \mathrm{~m}$ in the CBL. This can be put in relation with their average integral length scales of $153 \mathrm{~m}$ for $w$ and $207 \mathrm{~m}$ for $q$, that were computed from the high-resolution in situ data using the maximum of the autocorrelation function's integral following Lenschow and Stankov (1986). We conclude that intercomparisons of instantaneous CBL parameters are difficult to realise as they have to occur within small spatio-temporal separation. On the other hand, the comparison of leg-averaged fluxes, the chief objective of this study, does not require exact collocation.

The 'w' $q$ ' cospectrum of Figure 5 uses the same in situ $w$ data as Figure 4. It is computed with Eq. (2) using halfoverlapping segments with $n=8192$ data points that sum up to a length $T$ of $\sim 82 \mathrm{~s}$ or $L$ of $\sim 5.7 \mathrm{~km}$, as the aircraft speed was $\sim 70 \mathrm{~m} / \mathrm{s}$. While the frequency scale spans a

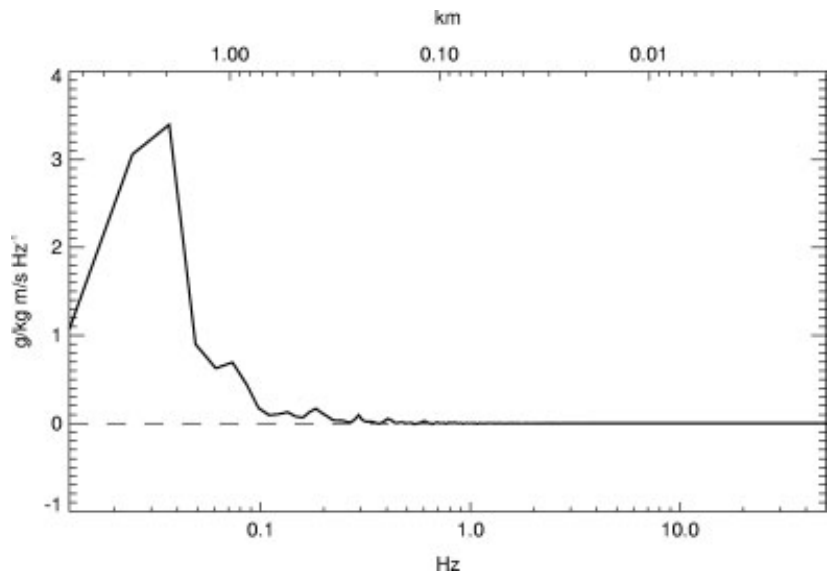

Figure 5. Cospectrum of vertical velocity (from Figure 4) and specific humidity of the $100 \mathrm{~Hz}$ in situ measurements along the northern part of leg F. Top axis is wavelength, assuming a constant aircraft speed of $70 \mathrm{~m} / \mathrm{s}$. The dominant contribution to the turbulent humidity flux has scales larger than $\sim 700 \mathrm{~m}$, with a peak between 2 and $3 \mathrm{~km}$ in wavelength. The cospectra of the other mountain flight legs are similar.

range of $1 / T=0.0122 \mathrm{~Hz}$ to $50 \mathrm{~Hz}$, the Nyquist frequency, the corresponding wavelength scale ranges from $5.7 \mathrm{~km}$ to $2 \cdot L / n=1.4 \mathrm{~m}$. The fact that large-scale turbulent elements contribute most to the net flux, as observed in Figure 3, is corroborated in Figure 5 by a distinct peak at wavelengths of $2-3 \mathrm{~km}$. Figure 5 is representative since all cospectra of this day (not shown here) peak between wavelengths of 1 and $3 \mathrm{~km}$, corresponding to $0.8-2.3 z_{i}$. The high-resolution data prove that turbulent diffusion on scales smaller than $\sim 700$ $m$ does not significantly contribute to the overall net flux in the mid-CBL over complex terrain. An evident explanation is that the small-scale up- and downdraughts balance on average. The fact that large-scale turbulent elements contribute most to the net flux has already been observed in strong convection over flat terrain (Duncan and Schuepp, 1992; Kiemle et al., 2007) and over the Black Forest during the VERTIKATOR experiment (Barthlott et al., 2006). The in situ data corroborate this mid-CBL behaviour essential to our study, where otherwise the spatial lidar resolution would not suffice to resolve the flux.

Integration of the cospectrum of Figure 5 using Eq. (3) gives a net humidity flux of $0.136 \mathrm{~g} / \mathrm{kg} \mathrm{m} / \mathrm{s}$, in coincidence with the covariance < $w^{\prime} q^{\prime}>$ averaged over all segments, as well as with the average of the CCF's zero-lag value over all segments, according to the analogy mentioned in section 3.3. In Figure 6 this in situ result is superposed on the lidar-derived latent heat flux profile from the northern part of leg $\mathrm{F}$ along the same $45 \mathrm{~km}$ path as the in situ data, between 48.3 and $48.7^{\circ} \mathrm{N}$. The agreement is well within the one-sigma lidar flux uncertainties displayed using Eq. 2 of 


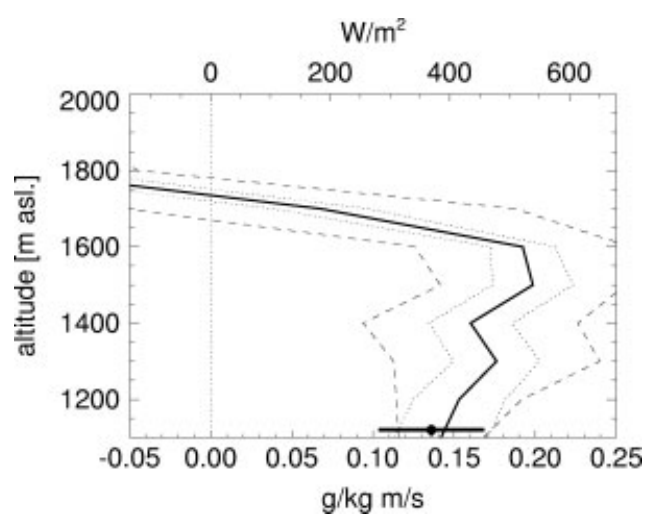

Figure 6. Profile of mid- to upper CBL latent heat flux (top axis) and kinematic humidity flux (bottom axis) from airborne water vapour and wind lidars along flight leg F on 30 July 2007, 1119-1124 UTC, corresponding to a length of $48 \mathrm{~km}$. Included are sampling (thin dashed) and noise (thin dotted) uncertainty ranges, plus an in situ result (black dot with sampling uncertainty bar) from the collocated Do-128 aircraft (1113-1125 UTC) with data from Figures 4 and 5. The average CBL top is around $1700 \mathrm{~m}$ asl.

Kiemle et al.(2007) for the sampling uncertainty and their Eq. 3 for the instrumental noise. The uncertainty evaluations involve the effective leg length (data gap widths subtracted), the variances and covariances of $w$ and $q$, and the integral length scales of the fluxes. The lidar noise is almost constant with height, thanks to the favourable top-down viewing where the signal decrease with lidar range is compensated by an increase of humidity and aerosol densities towards the ground. The in situ sampling uncertainty is $24 \%$, also calculated using Eq. 2 of Kiemle et al.(2007). It is close to the lidar's sampling uncertainty at the corresponding altitude since nearly the same air mass is probed. Under this condition the sampling uncertainty is irrelevant to the intercomparison. The scatter in the flux profile is smaller than the uncertainties and hence insignificant. In the entrainment zone above the well-mixed CBL the flux decreases to zero and below. The scattered cumulus clouds acting as sinks or sources of water vapour likely impinge on the flux profile in this transition region. A quantification of cloud-induced fluxes by lidar is however impossible since the clouds are opaque.

Figures 7 and 8 display the latent heat flux profiles of the two other flight legs of Figure 2 above the northern Black Forest. Overall, no large flux divergence or change of flux with height is observed. Linear regression analyses show that leg F (Figure 6) has a positive CBL flux divergence of $0.45 \mathrm{~g} / \mathrm{kg}$ $\mathrm{h}^{-1}$, leg E (Figure 7) is nearly neutral with $-0.03 \mathrm{~g} / \mathrm{kg} \mathrm{h}^{-1}$, and leg G (Figure 8) is slightly negative with $-0.15 \mathrm{~g} / \mathrm{kg}$ $\mathrm{h}^{-1}$. The regression analyses are performed across the mid-CBL profile range, i.e. $1100-1500 \mathrm{~m}, 800-1400 \mathrm{~m}$ and $900-2200 \mathrm{~m}$ asl in Figures 6 to 8, respectively. As detailed in the next section, a negative (positive) flux divergence humidifies (dries) the CBL in the absence of humidity advection. The flux divergences are too weak to be substantiated by measurements of $\mathrm{d} q / \mathrm{d} t$. For an optimal match with the Dornier-128 in situ fluxes, only the northern $45 \mathrm{~km}$ of the $130 \mathrm{~km}$ long Falcon legs are used, leading to high sampling uncertainties of between 30 and $100 \%$. They are however irrelevant to the comparison if the same air mass is probed, as explained above. Using the full lidar legs is not practical due to different orography in the southern part of the Black Forest (Figure 2). The lidar's sampling uncertainties are larger than the in situ

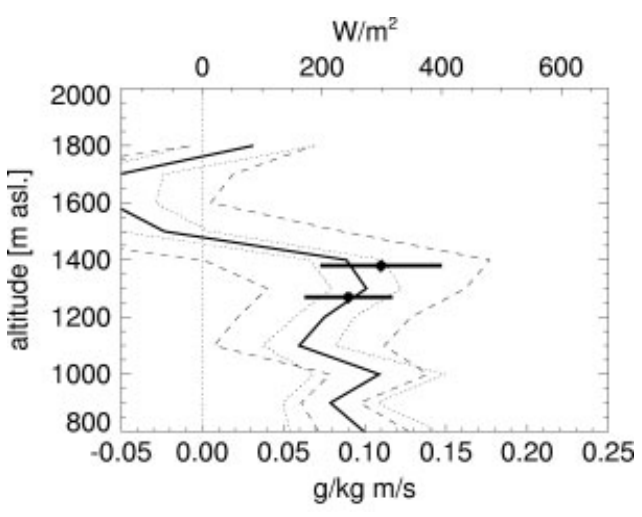

Figure 7. Latent heat flux profile from airborne lidar data of Figure 3 (leg E), with in situ results from 1057 to 1109 UTC $(1270 \mathrm{~m})$ and 1129 to 1141 UTC $(1380 \mathrm{~m})$ along the same leg. The average CBL top is around $1500 \mathrm{~m}$ asl (Figure 3).

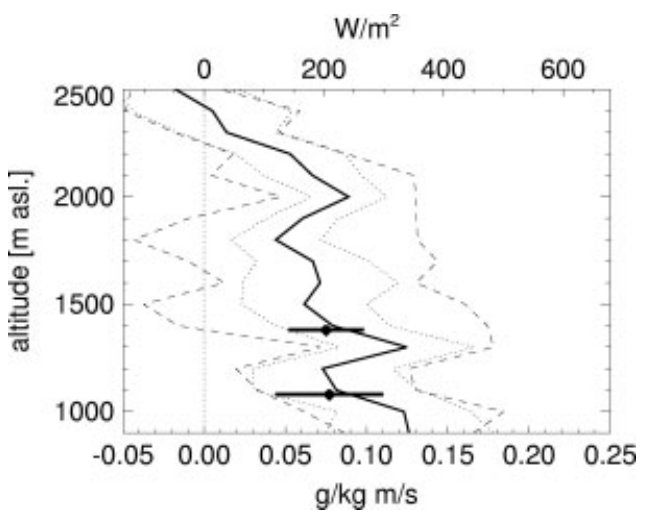

Figure 8. Latent heat flux profile from airborne lidars along flight leg $\mathrm{G}$, 1201-1205 UTC, $44 \mathrm{~km}$ long, with in situ results from 1022 to 1028 UTC $(1080 \mathrm{~m})$ and 1200 to 1210 UTC $(1380 \mathrm{~m})$ along the same leg. The average CBL top is around $2300 \mathrm{~m}$ asl.

error bars because of the clouds that reduce the effective leg lengths. The profiles in Figures 6, 7 and 8 vary considerably between 100 and $500 \mathrm{~W} / \mathrm{m}^{2}$ but are all positive in the CBL, in agreement with results of previous measurements over these mountains (Hasel, 2006). They allow, in total, five intercomparisons at different CBL altitudes, air traffic restrictions not permitting co-ordinated flights over the Rhine valley. Three comparisons are collocated in space and time; two are separated in time by 30 and 98 minutes. The latter corresponds to a cross-track shift of $\sim 15 \mathrm{~km}$ by the mean wind $(2.5 \mathrm{~m} / \mathrm{s})$ which is about one-third of the leg length. Comparisons are still possible as the average mid-CBL turbulence is not expected to change significantly over that time span. The results are very satisfying: the leg averages scatter by $\pm 20 \%$ which is well within the dotted lidar-noise flux uncertainties; the overall agreement is 3\%.

\subsection{Fluxes over the Rhine valley}

Rhine valley latent heat flux profiles from the DLR airborne lidars and from the ground-based lidars of COPS supersite $\mathrm{R}$ (see section 2.4) are shown in Figure 9. They agree within the airborne measurements' accuracy (thin lines). The time resolution of the BASIL Raman lidar and the Doppler lidar is $5 \mathrm{~s}$. In order to reduce statistical fluctuations in the water vapour and wind profiles an integration time of $75 \mathrm{~s}$ was chosen here. This gives a horizontal resolution of $\sim 200 \mathrm{~m}$, 


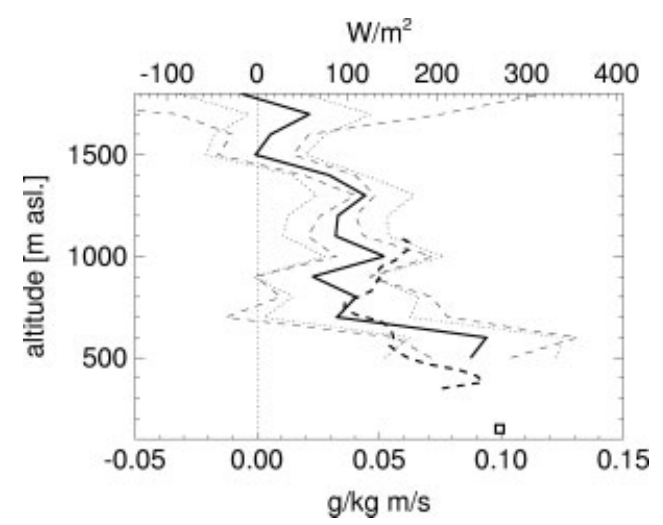

Figure 9. Latent heat flux profile (solid) from airborne lidars over the Rhine valley along the northern half of flight leg D, 1149-1155 UTC, $65 \mathrm{~km}$ long. Thick dashed: ground-based BASIL lidar profile from COPS supersite 'R' and surface in situ flux (box) from the Baden Airpark site (Figure 2). The average CBL top is around $1900 \mathrm{~m}$ asl.

similar to that of the airborne lidars, at the average wind velocity of $2.5 \mathrm{~m} / \mathrm{s}$. Proper synchronisation between Raman and Doppler lidar was achieved and carefully verified. Start and end time for all simultaneous $75 \mathrm{~s}$ average profiles from the Raman and Doppler lidars are always within $2 \mathrm{~s}$. The clocks of both lidar acquisition systems were synchronised to UTC via the network and additionally verified twice per day by a GPS clock. Based on the 75 s integration time, the random error affecting the water vapour mixing ratio measurement is $12 \%$ at $500 \mathrm{~m}$ asl, $22 \%$ at $1100 \mathrm{~m}$ and $55 \%$ at $1500 \mathrm{~m}$. Below $500 \mathrm{~m}$, because of the presence of an overlap region, the error increases, being $17 \%$ at $400 \mathrm{~m}$ and $50 \%$ at $300 \mathrm{~m}$. We therefore use only the measurements between 400 and $1100 \mathrm{~m}$ asl. The uncertainty is estimated by Poisson statistics, which is appropriate when the data are acquired in photon-counting mode as is the case with BASIL. The ground-based Doppler lidar's random error is $<0.1 \mathrm{~m} / \mathrm{s}$ in the CBL when integrated over $75 \mathrm{~s}$ (Pearson et al., 2009). The vertical resolutions of the water vapour and wind lidars are $150 \mathrm{~m}$ and $50 \mathrm{~m}$, respectively.

The BASIL lidar flux profile in Figure 9 is averaged between 1114 and 1157 UTC which corresponds to a spatial average across $6.5 \mathrm{~km}$ at a wind velocity of $2.5 \mathrm{~m} / \mathrm{s}$. Hence few convection cells are sampled and the corresponding uncertainty is large. The distance between supersite $\mathrm{R}$ and the northern part of leg $\mathrm{D}$ is $\sim 15 \mathrm{~km}$ or about a quarter of the airborne lidar's measurement length (Figure 2) over which horizontal homogeneity in the valley is observed. The radiosonde at site $\mathrm{R}$ measured north-westerly winds in the CBL. The mesoscale analysis of the COSMO-DE (Consortium for Small-scale Modelling) model of the German weather service agrees with the radiosonde data and shows synoptically forced flow from the valley to the mountains. Although we cannot completely rule out orographic influence due to the foothills' vicinity, the largescale flow towards the mountains gives a favourable fetch for the ground-based profiles, ensuring that undisturbed Rhine valley air was sampled. A similar CBL top height of $\sim 2 \mathrm{~km}$ asl in both lidar humidity profiles sustains the probable coincidence of probed air masses. The agreement between the airborne and ground lidar flux profiles is fairly good. A recent study with another ground-based water vapour Raman lidar corroborates our finding that profiles of turbulent variables in the CBL can in principal be obtained with such systems (Wulfmeyer et al., 2010).
Due to methodical constraints, airborne (ground) lidar fluxes cannot be retrieved below 350 (200) m asl, making comparisons with surface flux stations difficult. Nevertheless the Baden Airpark surface in situ latent heat flux, found to be constant between 1030 and 1200 UTC, roughly fits with an idealised linear extrapolation of the lidar profiles. Again, the favourable fetch owing to the weak north-westerly winds permits meaningful comparisons. The valley lidar flux profile has a divergence of $(-0.15 \pm 0.12) \mathrm{g} / \mathrm{kg} \mathrm{h}^{-1}$ determined by a linear regression analysis over the solid line of Figure 9 between 500 and $1400 \mathrm{~m}$ asl. The divergence uncertainty is obtained by using the sampling and noise uncertainty profiles as regression analysis weights. A linear latent heat flux profile is expected in a quasi-steady CBL with vertically constant advection, which seems fulfilled here, at least within the uncertainty bounds. Under the additional assumptions that the water vapour is conserved, i.e. does not undergo phase changes such as cloud condensation (true in the lower and mid-CBL), and that the horizontal flux divergence is negligible, the simplified CBL humidity budget equation relates the change of $q$ over time to the advection (second and third terms) and the vertical flux divergence (e.g. Stull, 1988):

$$
\frac{\partial q}{\partial t}+\bar{u} \frac{\partial q}{\partial x}+\bar{v} \frac{\partial q}{\partial y}+\frac{\partial\left\langle w^{\prime} q^{\prime}\right\rangle}{\partial z}=0 .
$$

The COSMO-DE mesoscale model analysis reveals that the advection of humidity in the investigated region can be neglected. The coarser European Centre for Medium-range Weather Forecasts (ECMWF) model analysis gives a similar result. Consequently the humidity change is balanced by the vertical flux divergence and amounts to $(0.15 \pm 0.12) \mathrm{g} / \mathrm{kg}$ $\mathrm{h}^{-1}$. This increase in CBL humidity over time is too small to be firmly observed by radiosonde or lidar. The positive fluxes with small vertical divergences found in Figures 6-9 signify a net upward humidity transport from the surface, the source of humidity due to rain on the two days before, to the free troposphere, entrained and moistened at the CBL top. Over the Rhine valley, the CBL depth grew by $150 \mathrm{~m} / \mathrm{h}$ or $0.04 \mathrm{~m} / \mathrm{s}$, as measured during two airborne lidar legs D around 1050 (not shown here) and 1150 UTC. Assuming the same CBL growth rate over the mountains (additional lidar legs are lacking), and given an average CBL top humidity jump of $3 \mathrm{~g} / \mathrm{kg}$ from the DIAL observations, a net upward flux of $3 \mathrm{~g} / \mathrm{kg} \cdot 0.04 \mathrm{~m} / \mathrm{s}=0.12 \mathrm{~g} / \mathrm{kg} \mathrm{m} / \mathrm{s}$ would be needed to maintain the CBL at constant humidity and to moisten the air entrained at the CBL top. This flux roughly corresponds to an average of all CBL fluxes in Figures 6-9, and thus corroborates our results. Although some likelihood for deep convection had been forecasted on 30 July 2007, and although moist convection was observed, one reason for the lack of thunderstorms on this day was probably the insufficient vertical humidity transport, the presence of water vapour at all levels being a prerequisite for latent heat release and deep convection.

The homogeneous conditions and the long flight legs in the Rhine valley enable more sophisticated investigations. Figures 10 and 11 are cospectra and spectra of vertical velocity and humidity across flight leg $\mathrm{D}$, computed with Eqs (2) and (1), respectively, after the method described in section 3.5. Vertical averages of individual mid-CBL spectra between 600 and $1400 \mathrm{~m}$ asl are displayed to improve the statistical significance. The results are consistent with a 


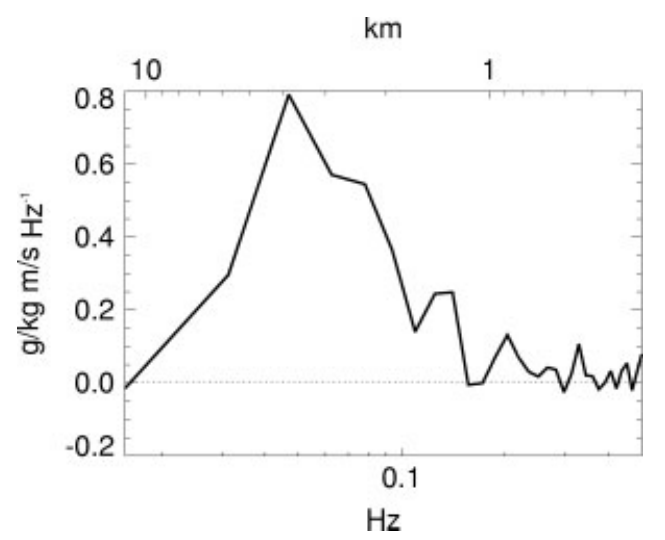

Figure 10. Mid-CBL cospectrum of vertical velocity and humidity from airborne lidars over the Rhine valley along flight leg D, 1143-1155 UTC, $127 \mathrm{~km}$ long. Axes as in Figure 5, except for an aircraft speed of $170 \mathrm{~m} / \mathrm{s}$ Scales smaller than $1 \mathrm{~km}$ do not contribute significantly to the net humidity flux.

Rhine valley lidar overflight performed one hour earlier (not shown here). Figure 10 shows a distinct peak between 2 and $5 \mathrm{~km}$ wavelength, at larger scales than in the in situ cospectra over the mountains (1-3 km; Figure 5). In agreement with the in situ data, no significant contribution to the flux is found at scales smaller than $1 \mathrm{~km}$. In the spectra of Figure 11 the inertial subrange is well visible in the almost noise-free Doppler wind lidar data, but suppressed by DIAL noise in the humidity spectrum. The broad maximum between wavelengths of $3-6 \mathrm{~km}$ is beyond the inertial subrange and likely due to mesoscale variability. Comparisons with the $45 \mathrm{~km}$ mountain lidar segments of the previous sections are impossible because of high DIAL noise and poor sampling. The aforementioned terrain heterogeneity between the northern and southern Black Forest mountains inhibits using the full length of legs E, F and G. Due to the limited on-site flight time of two hours, the pattern of Figure 2 could only be flown twice, and the relatively short flight legs implied many time-consuming aircraft turns. A recommendation for future mountain studies is hence to select regions with larger extent. Under the assumptions of homogeneous and isotropic turbulence in the inertial subrange, the one-dimensional vertical velocity spectrum $S_{w}(f)$ in Figure 11 allows estimating the turbulent kinetic energy (TKE) dissipation rate $\varepsilon$ using Obukhov's (1941) relationship

$$
S_{w}(k)=a \varepsilon^{2 / 3} k^{-5 / 3}, \varepsilon=\left(\frac{v}{a} \cdot S_{w}(f)\right)^{3 / 2} \cdot \lambda^{-5 / 2} .
$$

The second relationship holds for airborne measurements at the airspeed $v$, where wave number $(k)$ and frequency $(f)$ spectra are related via $S_{w}(k)=v \cdot S_{w}(f)$ (Hasel, 2006), since $k=\lambda^{-1}$ and $f=k \cdot v$ in the validity of Taylor's 'frozen turbulence' hypothesis (Stull, 1988). For a Kolmogorov constant $a=0.55$ for one-dimensional wind spectra, the TKE dissipation rate along the thin dotted line of Figure 11 within the inertial subrange between wavelengths of 0.4 and $1.3 \mathrm{~km}$ amounts to $(5 \pm 1) \cdot 10^{-4} \mathrm{~m}^{2} \mathrm{~s}^{-3}$. Since Figure 11 shows mid-CBL valley spectra averaged between 600 and $1400 \mathrm{~m}$ asl, this represents a mean energy dissipation rate across that range. It is in accordance with the mid-CBL results of the in situ vertical velocity spectra in the valley. Over the mountains, the in situ spectra show higher levels as expected and give TKE dissipation rates of up to $10^{-3} \mathrm{~m}^{2}$ $\mathrm{s}^{-3}$ at $1100 \mathrm{~m}$ asl.

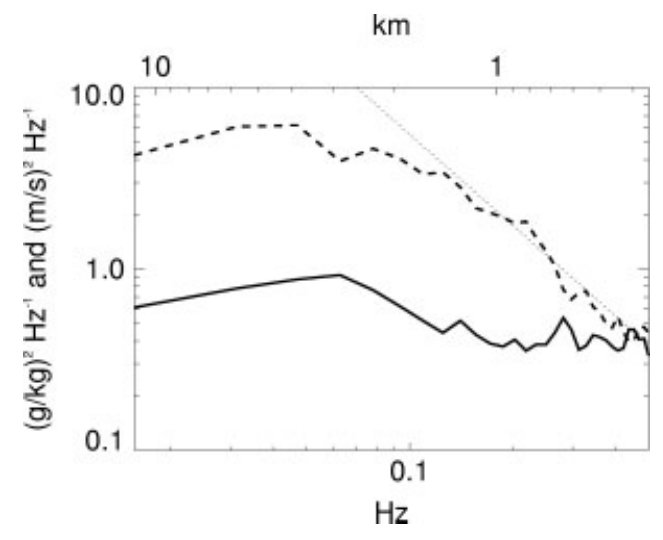

Figure 11. Mid-CBL spectra of vertical velocity (dashed) and humidity (solid) from airborne lidars over the Rhine valley along flight leg D, 1143-1155 UTC, $127 \mathrm{~km}$ long. While the velocity spectrum follows the turbulent kinetic energy dissipation cascade with a $-5 / 3$ slope (dotted) in the inertial subrange, the humidity data are too noisy to show that slope.

\section{Conclusions}

Airborne DIAL water vapour and Doppler wind lidar measurements of latent heat fluxes over complex terrain were performed in the frame of the COPS experiment with the aim of studying the variability of the initial field when convection initiation was predicted to be mainly influenced by orography and surface humidity. In the frame of a case-study on 30 July 2007, collocated flux measurements by airborne in situ sensors helped to refine and verify the methods used to compute fluxes. They show that instrumental noise and gaps in the lidar data due to scattered, small CBL-top clouds do not significantly bias the fluxes, and that the horizontal and vertical lidar resolution of $\sim 200$ $\mathrm{m}$ is sufficient to measure the net humidity flux in the midCBL, because the dominant contribution to the flux stems from large turbulent elements that have scales larger than $700 \mathrm{~m}$ or $\sim 0.5 z_{i}$. The lidar and in situ fluxes agree within $3 \%$ over five flight legs of $45 \mathrm{~km}$ length, i.e. over $225 \mathrm{~km}$ in total, the individual leg-averages ranging within $\pm 20 \%$. Due to the good collocation the agreement is independent of the large sampling uncertainty. The agreement is better than the lidar noise uncertainty, assessed with a formula from Kiemle et al.(2007), which indicates that the formula likely overestimates the uncertainty because of representing worst cases. As a matter of fact, fluxes and covariances agree better than the integral length scales and the variances, because the DIAL noise that constitutes the primary noise source and affects the humidity variances is not correlated with atmospheric turbulence and hence does not impinge on the covariances, as sensitivity tests with the in situ time series reveal.

The lidar-derived latent heat flux profiles in the mid- to upper CBL over the mountains vary significantly between different flight legs in the range of $100-500 \mathrm{~W} / \mathrm{m}^{2}$ but are roughly constant with height. The observed positive fluxes moisten the growing CBL by upward transport of humidity from the surface, from evaporation due to previous days' rain. The average turbulent flux amounts to $0.12 \mathrm{~g} / \mathrm{kg} \mathrm{m} / \mathrm{s}$ which corresponds to a latent heat flux of $\sim 300 \mathrm{~W} / \mathrm{m}^{2}$. This matches the lidar observation of a mean CBL growth of $150 \mathrm{~m} / \mathrm{h}$ and the radiosonde observations of constant CBL humidity. The fluxes were probably too low to generate the predicted deep convection on that particular day. A flight 
leg chosen as flat-terrain reference above the Rhine valley enabled comparisons with a ground-based lidar flux profile. The agreement is within the airborne lidars' accuracies and demonstrates the possibilities of ground-based water vapour Raman lidar, if the mean wind is favourable, i.e. if the wind velocity is high enough to ensure satisfactory air sampling and low enough to ensure sufficient small-scale resolution, given the Raman lidar's need to average adjacent profiles to reduce noise. We consider this study as a basis for future analyses of airborne lidar flux measurements over complex terrain and over ocean.

\section{Acknowledgements}

The authors gratefully acknowledge contributions to this work by Fay Davies (University of Salford), Thomas Aschenbrenner (KIT), Oliver Reitebuch, Andreas Schäfler, Rudolf Simmet and Hans Volkert (all DLR). The crews of both DLR Falcon and TU-Braunschweig Dornier128 aircraft did a great job in cooperating and in performing difficult flight patterns. The DLR Falcon participation in COPS was supported by the Deutsche Forschungsgemeinschaft (DFG) in the frame of the SPP1167 'Quantitative Precipitation Forecast' (grant WU 356/42). Our thanks are extended to the German weather service for the supply of the COSMO-DE mesoscale model and to Andreas Behrendt and Volker Wulfmeyer (University of Hohenheim) for the excellent co-ordination of the COPS experiment.

\section{References}

Aoshima F, Behrendt A, Bauer H-S, Wulfmeyer V. 2008. Statistics of convection initiation by use of Meteosat rapid scan data during the Convective and Orographically-induced Precipitation Study (COPS). Meteorol. Z. 17: 921-930.

Barthlott C, Corsmeier U, Meißner C, Braun F, Kottmeier C. 2006. The influence of mesoscale circulation systems on triggering convective cells over complex terrain. Atmos. Res. 81: 150-175.

Behrendt A, Pal S, Aoshima F, Bender M, Blyth A, Corsmeier U, Cuesta J, Dick G, Dorninger M, Flamant C, Di Girolamo P, Gorgas T, Huang Y, Kalthoff N, Khodayar S, Mannstein $\mathrm{H}$, Träumner K, Wieser A, Wulfmeyer V. 2011. Observation of convection initiation processes with a suite of state-of-the-art research instruments during COPS IOP 8b. Q. J. R. Meteorol. Soc. 137(S1): 81-100, DOI: 10.1002/qj.758.

Behrendt A, Wulfmeyer V, Di Girolamo P, Kiemle C, Bauer H-S, Schaberl T, Summa D, Whiteman DN, Demoz BB, Browell EV, Ismail S, Ferrare R, Kooi S, Ehret G, Wang J. 2007a. Intercomparison of water vapor data measured with lidar during IHOP 2002. Part I: Airborne to ground-based lidar systems and comparisons with chilled-mirror hygrometer radiosondes. J. Atmos. Oceanic Technol. 24: 3-21.

Behrendt A, Wulfmeyer V, Kiemle C, Ehret G, Flamant C, Schaberl T, Bauer H-S, Kooi S, Ismail S, Ferrare R, Browell EV, Whiteman DN. 2007b. Intercomparison of water vapor data measured with lidar during IHOP_2002. Part II: Airborne-to-airborne systems. J. Atmos. Oceanic Technol. 24: 22-39.

Bennett LJ, Blyth AM, Burton RR, Gadian AM, Weckwerth TM, Behrendt A, Di Girolamo P, Dorninger M, Lock S-J, Smith VH, Mobbs SD. 2011. Initiation of convection over the Black Forest mountains during COPS IOP15a. Q. J. R. Meteorol. Soc. 137(S1): $176-189$.

Bhawar R, Di Girolamo P, Summa D, Flamant C, Althausen D, Behrendt A, Kiemle C, Bosser P, Cacciani M, Champollion C, Di Iorio T, Engelmann R, Herold C, Pal S, Wirth M, Wulfmeyer V. 2011. The water vapour intercomparison effort in the framework of the Convective and Orographically-Induced Precipitation Study: airborne-to-ground-based and airborne-to-airborne lidar systems. Q. J. R. Meteorol. Soc. 137(S1): 325-348, DOI: 10.1002/qj.697.

Chaboureau JP, Richard E, Pinty JP, Flamant C, Di Girolamo P, Kiemle C, Behrendt A, Chepfer H, Chiriaco M, Wulfmeyer V. 2011. Long-range transport of Saharan dust and its radiative impact on precipitation forecast: a case study during the Convective and Orographicallyinduced Precipitation Study (COPS). Q. J. R. Meteorol. Soc. 137(S1): 236-251, DOI: 10.1002/qj.719.

Corsmeier U, Hankers R, Wieser A. 2001. Airborne turbulence measurements in the lower troposphere onboard the research aircraft Dornier 128-6, D-IBUF. Meteorol. Z. 10: 315-329.

Corsmeier U, Kalthoff N, Barthlott C, Behrendt A, Di Girolamo P, Dorninger M, Handwerker J, Kottmeier C, Mahlke H, Mobbs SD, Norton EG, Wickert J, Wulfmeyer V. 2011. Processes driving deep convection over complex terrain: a multi-scale analysis of observations from COPS IOP 9c. Q. J. R. Meteorol. Soc. 137(S1): 137-155, DOI: 10.1002/qj.754.

Davis JC, Collier CG, Davies F, Pearson GN, Burton R, Russell A. 2009. Doppler lidar observations of sensible heat flux and intercomparisons with a ground-based energy balance station and WRF model output. Meteorol. Z. 18: 155-162.

Dierer S, Arpagaus M, Seifert A, Avgoustoglou E, Dumitrache R, Grazzini F, Mercogliano P, Milelli M, Starosta K. 2009. Deficiencies in quantitative precipitation forecasts: Sensitivity studies using the COSMO model. Meteorol. Z. 18: 631-645.

Di Girolamo P, Summa D, Lin R-F, Maestri T, Rizzi R, Masiello G. 2009. UV Raman lidar measurements of relative humidity for the characterization of cirrus cloud microphysical properties. Atmos. Chem. Phys. 9: 8799-8811.

Duncan MR, Schuepp PH. 1992. A method to delineate extreme structures within airborne flux traces over the FIFE site. J. Geophys. Res. 97: 18487-18498.

Giez A, Ehret G, Schwiesow RL, Davis KJ, Lenschow DH. 1999. Water vapor flux measurements from ground-based vertically pointed water vapor differential absorption and Doppler lidars. J. Atmos. Oceanic Technol. 16: 237-250.

Hasel M. 2006. 'Strukturmerkmale und Modelldarstellung der Konvektion über Mittelgebirgen.' Thesis, 170 pp. Scientific report No. 39 of the Institute for Meteorology and Climate Research, Karlsruhe Institute of Technology (KIT), Germany.

Keil C, Röpnack A, Craig GC, Schumann U. 2008. Sensitivity of quantitative precipitation forecast to height dependent changes in humidity. Geophys. Res. Lett. 35: L09812, DOI: 10.1029/2008GL033657.

Kiemle C, Ehret G, Giez A, Davis KJ, Lenschow DH, Oncley SP. 1997. Estimation of boundary layer humidity fluxes and statistics from airborne differential absorption lidar (DIAL). J. Geophys. Res. 102: 29189-29203.

Kiemle C, Brewer WA, Ehret G, Hardesty RM, Fix A, Senff C, Wirth M, Poberaj G, LeMone MA. 2007. Latent heat flux profiles from collocated airborne water vapor and wind lidars during IHOP_2002. J. Atmos. Oceanic Technol. 24: 627-639.

Lenschow DH, Stankov BB. 1986. Length scales in the convective boundary layer. J. Atmos. Sci. 43: 1198-1209.

Lenschow DH, Wulfmeyer V, Senff C. 2000. Measuring second- through fourth-order moments in noisy data. J. Atmos. Oceanic Technol. 17: $1330-1347$.

Obukhov AM. 1941. Energy distribution in the spectrum of a turbulent flow. Izvestiya AN SSSR. Ser. Geogr. Geofiz. No. 4-5: 453-466.

Pearson G, Davies F, Collier CG. 2009. An analysis of the performance of the UFAM pulsed Doppler lidar for observing the boundary layer. J. Atmos. Oceanic Technol. 26: 240-250.

Press WH, Flannery BP, Teukolsky SA, Vetterling WT. 1988. Numerical Recipes in C: The Art of Scientific Computing. Cambridge University Press.

Richard E, Chaboureau JP, Flamant C, Champollion C, Hagen M, Schmidt K, Kiemle C, Corsmeier U, Barthlott C. 2011. Forecasting summer convection over the Black Forest: a case study from the Convective and Orographically-induced Precipitation Study (COPS) experiment. Q. J. R. Meteorol. Soc. 137(S1): 101-117, DOI: 10.1002/qj.710.

Schäfler A, Dörnbrack A, Kiemle C, Rahm S, Wirth M. 2010. Tropospheric water vapor transport as determined from airborne lidar measurements. J. Atmos. Oceanic Technol. 27: 2017-2030.

Senff C, Bösenberg J, Peters G. 1994. Measurement of water vapor flux profiles in the convective boundary layer with lidar and radar-RASS. J. Atmos. Oceanic Technol. 11: 85-93.

Stull RB. 1988. An Introduction to Boundary Layer Meteorology. Kluwer Academic Publishers.

Weckwerth TM, Wulfmeyer V, Wakimoto RM, Hardesty RM, Wilson JW, Banta RM. 1999. NCAR-NOAA lower-tropospheric water vapor workshop. Bull. Am. Meteorol. Soc. 80: 2339-2357.

Weckwerth TM, Parsons DB, Koch SE, Moore JA, LeMone MA, Demoz BR, Flamant C, Geerts B, Wang J, Feltz WF. 2004. An overview of the International $\mathrm{H}_{2} \mathrm{O}$ Project (IHOP_2002) and some preliminary highlights. Bull. Am. Meteorol. Soc. 85: 253-277. 
Weissmann M, Braun FJ, Gantner L, Mayr GJ, Rahm S, Reitebuch O. 2005. The Alpine mountain-plain circulation: Airborne Doppler lidar measurements and numerical simulations. Mon. Weather Rev. 133: 3095-3109.

Wirth M, Fix A, Mahnke P, Schwarzer H, Schrandt F, Ehret G. 2009. The airborne multi-wavelength water vapor differential absorption lidar WALES: System design and performance. Appl. Phys. B 96: 201-213.

Wulfmeyer V. 1999. Investigation of turbulent processes in the lower troposphere with water vapor DIAL and radar-RASS. J. Atmos. Sci. 56: 1055-1076.

Wulfmeyer V, Behrendt A, Bauer H-S, Kottmeier C, Corsmeier U, Blyth A, Craig GC, Schumann U, Hagen M, Crewell S, Di Girolamo P, Flamant C, Miller M, Montani A, Mobbs SD, Richard E, Rotach MW, Arpagaus M, Russchenberg H, Schlüssel P, König M, Gärtner V, Steinacker R, Dorninger M, Turner DD, Weckwerth TM, Hense A Simmer C. 2008. The Convective and Orographically induced Precipitation Study: A research and development project of the World Weather Research Program for improving quantitative precipitation forecasting in low-mountain regions. Bull. Am. Meteorol. Soc. 89: $1477-1486$

Wulfmeyer V, Pal S, Turner DD, Wagner E. 2010. Can water vapour Raman lidar resolve profiles of turbulent variables in the convective boundary layer? Boundary-Layer Meteorol. 136: 253-284.

Wulfmeyer V, Behrendt A, Kottmeier C, Corsmeier U, Barthlott C, Craig GC, Hagen M, Althausen D, Aoshima F, Arpagaus M, Bauer HS, Bennett L, Blyth A, Brandau C, Champollion C, Crewell S, Dick G, Di Girolamo P, Dorninger M, Dufournet Y, Eigenmann R, Engelmann R, Flamant C, Foken T, Gorgas T, Grzeschik M, Handwerker J, Hauck C, Höller H, Junkermann W, Kalthoff N, Kiemle C, Klink S, König M, Krauss L, Long CN, Madonna F, Mobbs SD, Neininger B, Pal S, Peters G, Pigeon G, Richard E, Rotach MW, Russchenberg H, Schwitalla T, Smith V, Steinacker R, Trentmann J, Turner DD, van Baelen J, Vogt S, Volkert H, Weckwerth TM, Wernli H, Wieser A, Wirth M. 2011. The Convective and Orographically-induced Precipitation Study (COPS): the scientific strategy, the field phase, and research highlights. Q. J. R. Meteorol. Soc. 137(S1): 3-30, DOI: 10.1002/qj.752. 